\title{
The impact of technology and a no remediation policy on non-traditional students
}

\author{
Clay Williams , Andrea C. Japzon
}

\begin{abstract}
A Hunter College librarian, with public library experience, offered a series of drop-in workshops Saturday afternoons open to all students and questions regarding Web or Windows use in the academic year, 2000-2001. The intention of the workshops was to address the continuous needs of students lacking technological and informational literacy. The success of these workshops led to this investigation of the implications of 21 st century technology on non-traditional students from the perspective of bibliographic instruction as well as reference desk service. The perspective is that of the urban educational environment of City University of New York and Hunter College. The histories of open admissions at CUNY and the current efforts to abolish remediation are examined.
\end{abstract}

In a December 2000, editorial in the New York Times, Arthur Levine, President of Teachers College, Columbia University, adding to the political and academic discussion on what the new vision of education should be, pointed out how the existing educational paradigms are shifting to meet the various realities of the information age. Levine questions the usefulness of the current methods of educating the masses in this time of specialization and diversity. He warns, "the old education system is dying and the biggest mistake we can make is to cling to the existing model of schooling. For those of us living through the change, it is easier to see 
what we are losing than what is emerging-a system of customized education for each" ( $p$. A33). He adds that this shift mirrors the one in the business world: mass production to specialized services. Largely because of technology, students will advance at individual rates, which the teacher, like a medical doctor, will have recognized, analyzed, and then delineated a course of study.

In the year 2000, the Chancellor of CUNY, Dr. Matthew Goldstein, submitted the requisite Four Year Master Plan to the Board of Trustees. This Master Plan calls for the phasing out of remedial coursework in the baccalaureate programs at the Senior Colleges (4-year colleges) and concurrently places new and significant emphasis on digital library collections. However, there are students, despite adequate academic qualifications when considered within the boundaries of the CUNY proficiency exams, who are still lacking in information technology skills. This community of students turns up at the Hunter College Library reference desk with continued regularity (The City University of New York, The City University of New York master plan, 2000-2004). Due to the students' anxiety about research, the librarians find themselves spending a great deal of time providing remedial one-on-one instruction on basic Web skills and sometimes even those required for Windows. The librarians have cast about for ways to assist these students, hoping to create some kind of "portal" these students may navigate and thus find themselves on the same plane as the other students in their classes. Nontraditional students are not addressable as a group as they do not appear in one place nor do they have a commonality. There are usually several in each class, which makes serving them problematic.

With the growing emphasis on digital collections and the tightening of standards, the need for remediation regarding technological competencies could easily be ignored. Where within the proficiency continuum would one put technological competencies, particularly where they overlap with information literacy? As technological competence becomes more widespread, there is an increased assumption that all students arrive in college with these unprecedented skills. Problems arise when this is not the case, and this is immediately apparent in the library. For example, e-mail and word processing are now necessary components of interactive learning and because the Hunter Libraries provides access to both as well as research instruction, student shortcomings are quickly apparent. Why can a classroom instructor make an assumption of knowledge but not a librarian? Where is it written that this is the librarians' job to instruct these students who are not fitting the "traditional student" profile?

Librarians have long recognized the need to address individual learning styles through a proven history of developing collections reflecting a diversity of perspectives, advocating intellectual freedom, and assessing point of need instruction (Bodi, 1990). Academic libraries, or more importantly, what they represent, have long held the position of campus technological and informational epicenters.

\section{Background}

In 1970, CUNY established an open admissions policy and straight away, the student body changed dramatically. In September 1970, 35,000 students began classes at CUNY, which 
signaled a $75 \%$ increase over the previous year. Many of the new CUNY students were older and members of a minority group. In fact, $80 \%$ of the black males enrolled in senior colleges in 1970 were open-admissions students, who were typically older than their "regular" classmates, those who would have been admitted before open admissions (Lavin \& Hyllegard, 1996, pp. $15,41-42)$. Hence, from the moment of open admissions, CUNY has had a significant number of students who would qualify as non-traditional students; this places CUNY ahead of the curve, nationally, in the number of such students registered. Patricia Breivik (1977) documented in the early 1970s the difficulties of CUNY students accessing the academic library. Colette Wagner (1988), in the late 1980s, defined the non-traditional student in a wellconstructed historical context, discussed the instructional architecture of academic librarianship, and then proposed some ways librarians could continue to teach the non-traditional student successfully.

The more diverse a student body becomes, the greater the need for such thinking as Levine advocates (2000). For example, given the increased presence of non-traditional students on college campuses today, the need for individualized attention is growing. A recent issue of the Reference Librarian (Kwasi, 2000) is dedicated to the topic of adult learners and includes articles on instruction for this population. One should note, however, certain types of nontraditional students are not covered, and this paper will attempt to define and then discuss them directly. Wagner examined the non-traditional student and bibliographic instruction in the City University of New York (CUNY) before the explosive impact of technology on information really took hold.

\section{Definitions of non-traditional students}

For the sake of continuity, and because they still apply to a remarkable degree, the five combinations of facts and attitudes or categories of Wagner (1988) shall be used. The five categories are academic, economic, social, experiential, and attitudinal. This definition of non-traditional or "new students" was first put forth by Cross (1971) and reinforced by Lavin, Alba, and Silberstein (1981) in their study of open admissions at CUNY.

Let us look at the CUNY Students of 2001 within the constraints of the five categories. Academically, CUNY students were and are at high risk in the traditional college classrooms. This is due to insufficient preparation at lower levels of the New York City public educational system. Currently, $60 \%$ of CUNY's entering first-year students graduated from New York City Public Schools, and almost 14\% are entering with a GED. A 1999 court case found the City's students were not receiving the basic education guaranteed by the State Constitution and were therefore not properly prepared for college (Goodnough, 1999, The ruling in the schools, 2001).

The CUNY student, generally speaking, still struggles economically and requires substantial financial assistance. This has not changed since Wagner's research in 1970, family income of the black and Hispanic students was half that of the white students' families. Many students schedule classes around work and family, and CUNY's administrators recognize this by offering classes in the evenings and on Saturdays (Office of the Registrar, $n$. d.). Furthermore, the electronic age has created the digital divide; a factor that has exacerbated 
the plight of economically challenged students (The City University of New York, CUNY student data fall, 2000).

Socially, CUNY students remain predominantly members of minority groups and are the first generation in their families to attend college. Over half of Hunter's first-year students speak a language other than English at home and over 35\% have green cards. Incidentally, while it is true that non-traditional students do expect college to translate into economic gains, at Hunter they are not as expectant of immediate occupational success because the school is a liberal arts college, rather they attend because of Hunter's long-standing reputation of quality.

The average age of the Hunter student is slightly over 26 and often, older students have adult responsibilities not observed at more traditional or residential campuses, such as child rearing and wage earning; therefore, the current students are experientially-similar to previous incarnations of the CUNY student. Wagner stated that non-traditional students "... attitudinally, are less likely to take college for granted, skeptical of authority, interested in exerting some 'ownership' rights over their own education, and [more] highly motivated..."(1988, p. 45). They are certainly well motivated, but because of the interplay of academic requirements with work and familial responsibilities, the non-traditional students' struggle is in part illustrated by how long it takes the average CUNY student to matriculate. The current average for matriculation is over seven years.

For the purposes of this paper, one or all of these categories define the non-traditional student. Too often, in library literature the older student represents the non-traditional student almost exclusively. Indeed, the older student does fit into at least one of these categories. However, so do numerous other students, for example, minority, economically disadvantaged, and first-generation students fit into at least one, if not more. The point here is that these categories are not mutually exclusive. One or all of these categories define the non-traditional student. By these definitions, non-traditional students are under represented in the instruction literature when compared to other groups. This is not to say that articles concerned with library instruction for students with disabilities or international students would not apply to nontraditional students. Perhaps, in the literature, instructional theories are not applied with consistency to the non-traditional student. For example, the affective learning steps so well described by Carol Kuhlthau (1994); would her paradigm need adjustment when applied to the non-traditional student affected by the digital divide?

\section{Case study}

Due to staffing shortages, it was concluded that a drop-in class would provide the seminal step in bringing academically qualified students up to expected technological understanding. The informal class, open to all students, regardless of subject or problem, allows the librarians to address individual learning styles. Saturdays and Wednesdays were chosen in part to address the nature of scheduling concerns for non-traditional students as well as to address the basic information skills that were consuming too much time at an already busy reference desk. The workshops were designed to include Windows, the Web, and increasingly needed e-mail skills (Guanine, 1999). 
While the Saturday workshop was much better attended, both workshop series resulted in attendance primarily by non-traditional students, as had been hoped (see Table 1). The high turnout of non-traditional students prompted this examination of the evolution of bibliographic instruction and the non-traditional student within CUNY particularly in light of the aforementioned 2000 Master Plan (The City University of New York, The City University of New York master plan, 2000-2004).

A general flyer was distributed to the various computing facilities on campus, student organizations, student counselors, and the office for students with disabilities. Signs were displayed in and around the library and a large sign was placed at the main entrance by the circulation desk. All library users were invited to attend. This included alumni, continuing education students, and students from other CUNY schools because on Saturdays many students from other CUNY schools use the Hunter College Library due to its central location on the Upper East Side of Manhattan.

The class design had little structure thus allowing for the individual learning styles and needs of the students. The classroom is equipped with 16 PCs and the classroom's circular arrangement of the computers facilitated the instructor's ability to check on each student's progress. Because the class was open to all questions and a variety of subjects, the lack of any specific design or topics to be covered may have attracted more students. Some issued addressed during class time were working in a Windows environment, search the Web using keyword and subject searching, and exploring several databases including InfoTrac and ERIC.

Attendance increased dramatically over the course of the semester. As assignments came due, the urgency for the skills taught in the class became greater. As indicated earlier, for the non-traditional student, time is a valuable commodity that only when things are desperate will students commit the necessary time to learning skills that do not necessarily produce a grade. The class design allowed the instructor to tailor instruction to individual needs at the same time students were encouraged to follow along or work independently.

Table 1

Attendance

\begin{tabular}{|c|c|c|}
\hline $\begin{array}{l}\text { Type of participant, } \\
\text { total for all classes }\end{array}$ & $\begin{array}{l}\text { Nine Saturday classes, } \\
\text { Spring } 2000\end{array}$ & $\begin{array}{l}\text { Four Wednesday classes, } \\
\text { Fall } 2000\end{array}$ \\
\hline Graduate student & 24 & 5 \\
\hline Undergraduate student & 12 & 4 \\
\hline Other & 4 & 0 \\
\hline Faculty & 2 & 0 \\
\hline Hunter/faculty student & 42 & 0 \\
\hline Non-hunter faculty/student & 0 & 0 \\
\hline Non-traditional student experientially ${ }^{\text {a }}$ & 38 & 9 \\
\hline Non-traditional student socially ${ }^{\mathrm{b}}$ & 10 & 1 \\
\hline Female student & 31 & 9 \\
\hline Male student & 11 & 0 \\
\hline
\end{tabular}

\footnotetext{
a Students over 30 years of age.

${ }^{\mathrm{b}}$ Foreign-born students.
} 
As a population, the students were mostly women over 40 who had returned to obtain a graduate degree. Another large subgroup was non-native English speakers. According to the answers given in the survey, the students either were motivated by a need to use the Web for class assignments or because they felt isolated from their peers due to their ignorance of the Web. Moreover, these are hardly exclusive sets; a student could certainly be a part of both groups.

Several students repeated the class; they enjoyed the support received from the other students in the workshop who were in the same predicament, as well as instructor encouragement. As previously mentioned, these individuals are fully qualified for their various fields of study by CUNY standards but because of a lack of exposure are not yet qualified to use information technology effectively. Within the framework of Christine Bruce's "faces" of information literacy, these students were barred from the more advanced of her categories because of their inadequately developed information technology conception. It can be posited that in order to use information properly and efficiently, one must first use information technology (Bruce, 1998).

Ascertaining the level of these students' information literacy is difficult because their lack of technological fluency does not allow them to begin to explore or understand the current research process. The students may well know important aspects of research within their field of study but because of a lack of experience in the technological environment, they are unable to implement sound research practices. As mentioned above, teaching and serving nontraditional students can be problematic when using the affective parameters developed with a more traditional student population; those measures, nevertheless, do provide an important baseline. The occurrences of anxiety described by Kuhlthau (1994) do not necessarily happen at the same point in the process for a student whose anxieties are connected to a lack of technological fluency. This anxiety is not of necessity related to the subject matter. The $A C R L$ Information Literacy Competency Standards for Higher Education (The Association of College and Research Libraries [ACRL], 2002) do necessarily describe the expected levels of information literacy in higher education. The discussions of fluency with information technology do not discuss the social implication involved with a lack of fluency. The challenge for librarians and classroom instructors is to educate systematically the nontraditional student in the spirit of the standards and doing this within the existing framework of higher education.

A short questionnaire was given at the end of each session. The questions were mainly open-ended, in part to see what concepts the students learned and in part to guide the instructor in subsequent classes. Given the nature of the participants and the context of the nontraditional student, future workshop questionnaires should require additional information from the students.

Fortunately, the students were quick learners, in spite of their limited exposure to the web and electronic resources. Typical of electronic information neophytes, they willingly believed the Web to be the ultimate information source, simply because it is technology based and was previously inaccessible to them. Furthermore, their naiveté regarding the need to evaluate information found on the Web was not at all different from most other students. Hence, these students very quickly joined their peers in this regard; once they achieve a modicum of 
information technology literacy they can bring into play their "dormant" critical thinking skills.

Just as Wagner found in 1988, the students of today are equally frustrated to learn that there is no quick and easy way to do research. Today's non-traditional students are no less loath to discover that the research process is arcane and the learning curve long. The realization that the dynamic nature of the research process will continue and therefore make information literacy an active part of the students' lifelong learning experience (Wagner, 1988, p. 46).

\section{Re-evaluating the tactics and the teaching library}

Wagner's themes provide historical context and the continuity of ideas regarding instruction. With assessment as a benchmark, we will examine how instructional tactics in Hunter's library have altered. The pedagogical landscape has changed dramatically, and therefore the tactics must change as well. For example, the online aspects of library research are more pervasive than ever, and the expectations regarding student computer skills are much higher. The question remains whether the patterns and tactics of instruction have kept pace with these changes.

At Hunter, the reference interview still pervades librarian-student interaction. Hunter has not yet seen the drop in the number of students coming to the reference desk witnessed by colleges with a more affluent student body, many of whom have computers in their dormitories. Indeed, the difficulties that arise do so because this remains a student-initiated phenomenon. The success of the reference interview in no small measure depends upon the student's being comfortable enough with the library and research process to initiate contact with the librarian.

Ironically, the class that instigated this study was prompted because the librarians were finding themselves spending an inordinate amount of time with very basic questions of computer literacy. Because of technology, librarians' points of interaction and intervention with the students are changing, even though Hunter is a bit behind the curve. The amount of change seen in library service over the last several decades combined with the increasingly diverse student population has caused library instruction to become a major consideration on all campuses. The reasons for such change often rest with the classroom professors' methods of teaching, not necessarily with a lack of change or effort in reference departments (Wagner, 1988, p. 49).

The prevailing literature in academic librarianship recommends librarians partner with the classroom faculty in ways that will make the purpose of the research session evident to the student. The successful collaboration must have both a research component and an assigned project. This, perhaps self-evident assumption, can make the difference for the students' understanding of the research process. Patricia Senn Breivik (1977) demonstrated the inherent danger of non-integrated library instruction. She found that students who experienced only a library tour were more negative about the library than those who had no tour at all. Her third group, however, received course-integrated instruction and felt more positively about the library than either of the other groups. 
ACRL and ALA guidelines for information literacy delineates the responsibilities of the librarian and the classroom professor (ACRL, Instructional Section, 2002). The dual nature of these guideline responsibilities acknowledges that information literacy is not the sole job of the librarians.

\section{Conclusion}

While the returning adult receives substantial coverage in educational and library literature, the other non-traditional students defined by Wagner's five categories and revisited in this article are not receiving such attention. When considering factors such as the digital divide and increased immigration, not to mention the economic tiering of students at many well-known universities, a broader definition of the non-traditional student needs to be utilized. Do colleges and universities have an overarching responsibility for the technological and information skills of every one of their enrolled students? Does the college library? Is it solely the student's responsibility? Can higher education hold students to technological standards without a systematic means of verifying the abilities of all students? If, as in CUNY, remediation is no longer an option, what options remain? (Kaufman, 2001).

The ACRL Information Literacy Competency Standards are helping to establish the responsibility of all parties involved. A possible first step for a college or university would be to adopt officially the responsibility tags ACRL sets out, thus defining what they feel can be reasonably accomplished by the student, the instructor, and the librarian. The standards acknowledge that students will progress through the stages of information literacy with varying speed. The learning process is indeed unique and relentlessly evolves as the student's journey through their education, and Levine, in his editorial counsels what society must expect and do. However, educators and librarians alike will agree that given the ubiquity of online information certain levels of information literacy must be expected of all students. When creating assignments, a professor should not have to consider whether a student knows how to save a web document to disk. Moreover, a librarian should be able to assume that a student can find the location box on a web browser. In our experience, the non-traditional student often falls short of meeting these expectations. However, we can create "portals" for educating the students who slip through the cracks.

An honest acknowledgment of non-traditional students is only possible when one carefully defines them. Once defined, librarians can consider their needs in light of the services the library provides. The success of these workshops helped to define non-traditional students in terms of information literacy. By allowing for individual learning styles and varying levels of academic and technological knowledge, librarians provided bibliographic instruction more in tune with the reality of the students of the 21 st century.

\section{References}

Bodi, S. (1990). Teaching effectiveness and bibliographic instruction: The relevance of learning styles. College and Research Libraries, 51(2), 113-119 (March). 
Breivik, P. S. (1977). Open admissions and the academic library. Chicago: American Library Association.

Bruce, C. S. (1998). The phenomenon of information literacy. Higher Education Research and Development, $17(1), 25-43$.

Cross, P. K. (1971). Beyond the open door San Francisco: Jossey-Bass.

Goodnough, A. (1999). The schools and the constitution. New York Times, 149, A26 (October 22).

Guanine, G. (1999). Drop-in session: Information literacy responding to student needs.Australian Academic and Research Libraries, 30, 212-218 (September).

Kaufman, J. (2001). At elite universities, a culture of money highlights class divide. Wall Street Journal, A1 (June 8).

Kuhlthau, C. C. (1994). Teaching the library research process, 2nd ed. Lanham, MD: Scarecrow Press.

Kwasi, S-M. (Ed.). (2000). The Reference librarian: Reference services for the adult learner: Challenging issues for the traditional and technological era New York: Haworth Information Press Inc.

Lavin, D., \& Hyllegard, D. (1996). Changing the odds: Open admissions and the life chances of the disadvantaged. New Haven: Yale University Press.

Lavin, D. E., Alba, R. D., \& Silberstein, R. A. (1981). Right versus privilege: The open admissions experiment at the City University of New York New York: Free Press.

Levine, A. (2000, December 22). Tomorrow's education, made to measure. New York Times, p. A33 (late edition).

Office of the Registrar. Hunter College Schedule of Classes. Retrieved April 11, 2002, from http://registrar.hunter. cuny.edu/schedule/index.htm

The Association of College and Research Libraries [ACRL]. Information Literacy Competency Standards for Higher Education. Retrieved April 10, 2002, from http://www.ala.org/acrl/ilintro.html

The Association of College and Research Libraries [ACRL], Instructional Section. Objectives for Information Literacy Instruction Model Statement for Academic Librarians. Retrieved April 7, 2002, from http://www.ala. org/acrl/guides/objinfolit

The City University of New York. CUNY student data fall 2000 [Data file]. Retrieved January 3, 2007, from http:// www.cuny.edu/abtcuny/facts/data_fall2001/index.html

The City University of New York. The City University of New York master plan 2000-2004. Retrieved April 10, 2002, from http://www.cuny.edu/topframe-abtcuny.html

The Ruling in the schools: The overview; state judge rules school aid system is unfair to city. (January 11, 2001). New York Times, p. 1, Col 6.

Wagner, C. A. in consultation with Kappner, Augusta S. (1988). The academic library and the non-traditional student. In P. S. Breivik, \& R. Wedgeworth (Eds.), Libraries and the search for academic excellence (pp. 43-56). Metuchen, NJ: Scarecrow Press. 